\title{
Recent Advances in Thermally and Photochemically Initiated Cationic Polymerization
}

\author{
James V. CRIVELLO and J. L. LEE \\ General Electric Corporate Research and Development, \\ Schenectady, New York 12301, U.S.A.
}

(Received August 20, 1984)

\begin{abstract}
Several new classes of triarylsulfonium salts have been discovered which possess enhanced efficiency as photoinitiators of cationic polymerization. One of these compounds was identified among the components of the Friedel Crafts reaction of benzene with sulfur monochloride and chlorine. Specific new syntheses were developed and are described for the synthesis of these compounds in high yields. The development of several new thermal initiator systems for cationic polymerization based on dialkyl-4-hydroxyphenylsulfonium and dialkylphenacylsulfonium salts is also discussed.
\end{abstract}

KEY WORDS Photoinitiated Cationic Polymerization / Triarylsulfonium Salts / Diphenyl-4-thiophenoxyphenylsulfonium Salts / Thermally Initiated Cationic Polymerization / Dialkyl-4-hydroxyphenylsulfonium Salts / Dialkylphenacylsulfonium Salts /

During the past several years, work in our laboratory has focused on the development of novel photoinitiators for cationic polymerization. Among the most practical of the several classes of these photoinitiators which we have investigated are the triarylsulfonium salts. ${ }^{1}$ These compounds are easily prepared by straightforward synthetic methods and have high photosensitivities. Moreover, those salts bearing non-nucleophilic anions are powerful initiators of cationic polymerization capable of polymerizing a wide variety of vinyl and heterocyclic monomers. One serious drawback, however, is the poor spectral response of most simple triarylsulfonium salts. These compounds absorb strongly only in the short wavelength UV (below $250 \mathrm{~nm}$ ). It was one of the objectives of the present work to design photoinitiatiors based on triarylsulfonium salt chemistry which would have absorption maxima in the mid to long wavelength region of the UV.

A second research objective was to investigate the possibility of the devising of cationic initiator systems based on sulfonium salt chemistry which could be triggered thermally rather than photochemically.

\section{EXPERIMENTAL}

\section{Materials}

All reagents and starting materials used in the synthesis of the sulfonium salts were reagent grade and were used without purification. The synthesis of diaryliodonium salts used as precursors for the synthesis of triarylsulfonium salts has been described previously. ${ }^{2,3}$ Similarly, the synthesis of dialkyl-4-hydroxyphenylsulfonium and dialkylphenacylsulfonium salt photoinitiators has also been reported by us. ${ }^{4,5}$ The heterocyclic arylsulfides, dibenzothiophene, thioxanthene, thianthrene and phenoxanthin used for the preparation of the triarylsulfonium salts shown in Table II were purchased from several sources and used as received. Cyclohexene oxide, styrene oxide, and limonene dioxide were dried and then purified by fractional distillation from calcium hydride. Photoinitiated cationic polymerizations of limonene dioxide were followed by photomicrocalorimetry using an apparatus which has been described earlier. ${ }^{6}$ Typical irradiation and isolation techniques were used in the thermal and photopolymerization of cyclohexene oxide and styrene oxide. ${ }^{1}$ 


\section{J. V. Crivello and J. L. LeE}

Preparation of Impure "Triphenylsulfonium Hexafluoroarsenate" by the Method of Pitt ${ }^{8}$

Into a $2000 \mathrm{ml}$ three-necked round-bottomed flask equipped with a reflux condenser, $\mathrm{CaCl}_{2}$ drying tube, mechanical stirrer and thermometer were placed $700 \mathrm{ml}$ of benzene and $215 \mathrm{~g}$ of anhydrous $\mathrm{AlCl}_{3}$; the mixture was then agitated. Next, $135 \mathrm{~g}$ of $\mathrm{S}_{2} \mathrm{Cl}_{2}$ were added via an addition funnel while the temperature was maintained between $10-15^{\circ} \mathrm{C}$ with the aid of an ice-salt bath. This part of the reaction was highly exothermic. After the exotherm had subsided, the reaction flask was fitted with a fritted gas inlet tube and chlorine gas was sparged into the reaction mixture at a moderate rate for $90 \mathrm{~min}$ while the temperature was maintained between $10-15^{\circ} \mathrm{C}$. Chlorine addition was continued until a total of $175 \mathrm{~g}$ had been added and the reaction was dark black and thixotropic. The entire reaction mixture was transferred to an addition funnel and slowly was added to $600 \mathrm{ml}$ water contained in a $2000 \mathrm{ml}$ flask equipped with a paddle stirrer, a reflux condenser and a discharge valve located at the bottom of the flask. After hydrolysis was complete, the reaction mixture separated into two layers and the bottom layer, consisting of a strong acidic $\mathrm{AlCl}_{3}$ solution was drawn off and discarded. An additional $500 \mathrm{ml}$ water was added with agitation and the bottom layer drawn off as a pale yellow, slightly viscous solution.

To $29.8 \mathrm{~g}$ of the above solution, containing approximately $50 \%$ triarylsulfonium chloride salts, there were added $100 \mathrm{ml}$ distilled water and $11.4 \mathrm{~g}$ $(0.05 \mathrm{~mol})$ of $\mathrm{KAsF}_{6}$ dissolved in $400 \mathrm{ml}$ of water. The white precipitate which formed was collected by filtration, washed with water and dreid in vacuo to give $19 \mathrm{~g}(74 \%$ based on weight $)$ of a product melting at $90-113^{\circ} \mathrm{C}$.

The Synthesis of Arylsulfide Intermediates Used in the Preparation of the Compounds in Table I

To a $250 \mathrm{ml}$ round-bottomed flask equipped with condenser, Dean-Stark trap and thermometer there were placed $19.6 \mathrm{~g}(0.35 \mathrm{~mol})$ of $86 \% \mathrm{KOH}, 33 \mathrm{~g}$ $(0.3 \mathrm{~mol})$ of thiophenol and $120 \mathrm{ml}$ of dimethylacetamide. The mixture was heated at $150^{\circ} \mathrm{C}$ and $6.5 \mathrm{ml}$ water were collected. To the potassium thiophenoxide solution there were added $26.3 \mathrm{~g}(0.11 \mathrm{~mol})$ of $o-, m-$, or $p$-dibromobenzene and the reaction mixture was heated to reflux for $6 \mathrm{~h}$. In the cases in which 4-bromobiphenyl or 4-bromophenyl phenyl ether were used as substrates, $0.22 \mathrm{~mol}$ of these compounds were employed. After cooling, the reaction mixture was added to $300 \mathrm{ml}$ water and the precipitated arylsulfide was collected by filtration, washed with water and air-dried overnight. In most cases the arylsulfide was sufficiently pure to be used directly in the subsequent arylation. However, in some cases the arylsulfide was recrystallized usually from ethanol.

\section{The Preparation of Authentic Diphenyl-4-thio-} phenoxyphenylsulfonium Hexafluoroarsenate (IV) The following is a typical arylation procedure which was employed in the preparation of all of the triarylsulfonium salts shown in Tables I and II. In this example it has been used for the synthesis of authentic diphenyl-4-thiophenoxyphenylsulfonium hexafluoroarsenate.

Combined together in a $50 \mathrm{ml}$ round-bottomed flask were $7.35 \mathrm{~g}(0.025 \mathrm{~mol})$ of the above disulfide, $11.75 \mathrm{~g}(0.025 \mathrm{~mol})$ of diphenyliodonium hexafluoroarsenate and $0.2 \mathrm{~g}$ copper benzoate. The mixture was heated for $3 \mathrm{~h}$ at $120^{\circ} \mathrm{C}$ in an oil bath. On cooling, the light brown reaction mixture was washed several times with $50 \mathrm{ml}$ portions of diethyl ether to remove the iodobenzene and the remaining solid was recrystallized from $95 \%$ ethanol to give $6.3 \mathrm{~g}$ pure, very light tan, crystalline sulfonium salt (mp 76-77 ${ }^{\circ}$ ). Anal. Calcd for $\mathrm{C}_{24} \mathrm{H}_{19} \mathrm{AsF}_{6} \mathrm{~S}_{2}: \mathrm{C}$, $51.42 \%$; H, $3.40 \%$; S, $11.43 \%$. Found: C, $51.21 \%$; $\mathrm{H}, 3.59 \%$; S, $11.37 \%$.

\section{Preparation of IV from Diphenyl Sulfide}

Into a $250 \mathrm{ml}$ round-bottomed flask was placed $37.2 \mathrm{~g}(0.2 \mathrm{~mol})$ of diphenylsulfide and $13.34 \mathrm{~g}$ of aluminum chloride. To this mixture, chlorine was introduced through a gas inlet tube. A total of $9.5 \mathrm{~g}$ of chlorine was added during which the color of the reaction became quite dark black. The reaction was quenched by pouring it onto $500 \mathrm{~g}$ ice to decompose the aluminum chloride complex. A white semisolid was obtained which was washed twice with $200 \mathrm{ml}$ portions of hot water. Next, $22.8 \mathrm{~g}(0.1 \mathrm{~mol})$ of $\mathrm{KAsF}_{6}$ in $500 \mathrm{ml}$ hot water were added. The orange colored oil which separated was recovered by decanting the aqueous solution and was purified by successively washing with water and finally with anhydrous ether. The sulfonium salt was dried in vacuo at $60^{\circ} \mathrm{C}$ for $16 \mathrm{~h}$. The salt could be further purified by recrystallization from $95 \%$ ethanol using 
charcoal. An overall yield of $31 \%(17.5 \mathrm{~g})(\mathrm{mp} 78$ $79^{\circ} \mathrm{C}$ ) of a sulfonium salt was obtained which was identical in all respects with that described in the previous experiment.

\section{RESULTS AND DISCUSSION}

\section{Photochemically Initiated Cationic Polymerization}

During our recent investigations of triarylsulfonium salt photoinitiators, we had the occasion to prepare triphenylsulfonium salts by several synthetic methods. Pure triphenylsulfonium salts obtained, for example, by the reaction of diphenylsulfoxide with phenylmagnesium chloride ${ }^{7}$ have a single absorption band at $227 \mathrm{~nm}$ in the UV. At the same time, the method described by $\mathrm{Pitt}^{8}$ consisting of the condensation of benzene with sulfur



Figure 1. UV spectrum of triarylsulfonium salts prepared by the method of Pitt (in $\mathrm{CH}_{3} \mathrm{OH}$ ). monochloride and chlorine in the presence of aluminum chloriade yields impure "triphenylsulfonium chloride" which when converted by metathesis to its hexafluoroarsenate salt gave the UV spectrum shown in Figure 1. The spectrum clearly shows that in addition to the $227 \mathrm{~nm}$ band there is a new broad band at approximately $300 \mathrm{~nm}$. Further, the ${ }^{13} \mathrm{C}$ NMR spectrum shown in Figure 2 contains in addition to the indicated four peaks assigned to the triphenylsulfonium salt, several extraneous peaks suggesting the presence of other sulfonium salt(s) with closely related structure(s). When this latter mixture was used to photoinitiate cationic polymerization, we were surprised and delighted to note that the mixture was more efficient as a photoinitiator than the analogous pure triphenylsulfonium salt. In these studies, unfiltered medium pressure mercury arc lamps were used which deliver the full mercury line spectrum. It was concluded from these results that those components present in the mixture responsible for the long wavelength absorption band may be better photoinitiators either because they have higher quantum yields of photolysis or because they absorb more strongly at the wavelengths emitted by the irradiation source.

With these observations and conclusions in mind, it was decided to attempt to isolate and characterize those compounds present in the mixture of sulfonium salts which may be responsible for the long wavelength absorption and higher photo-

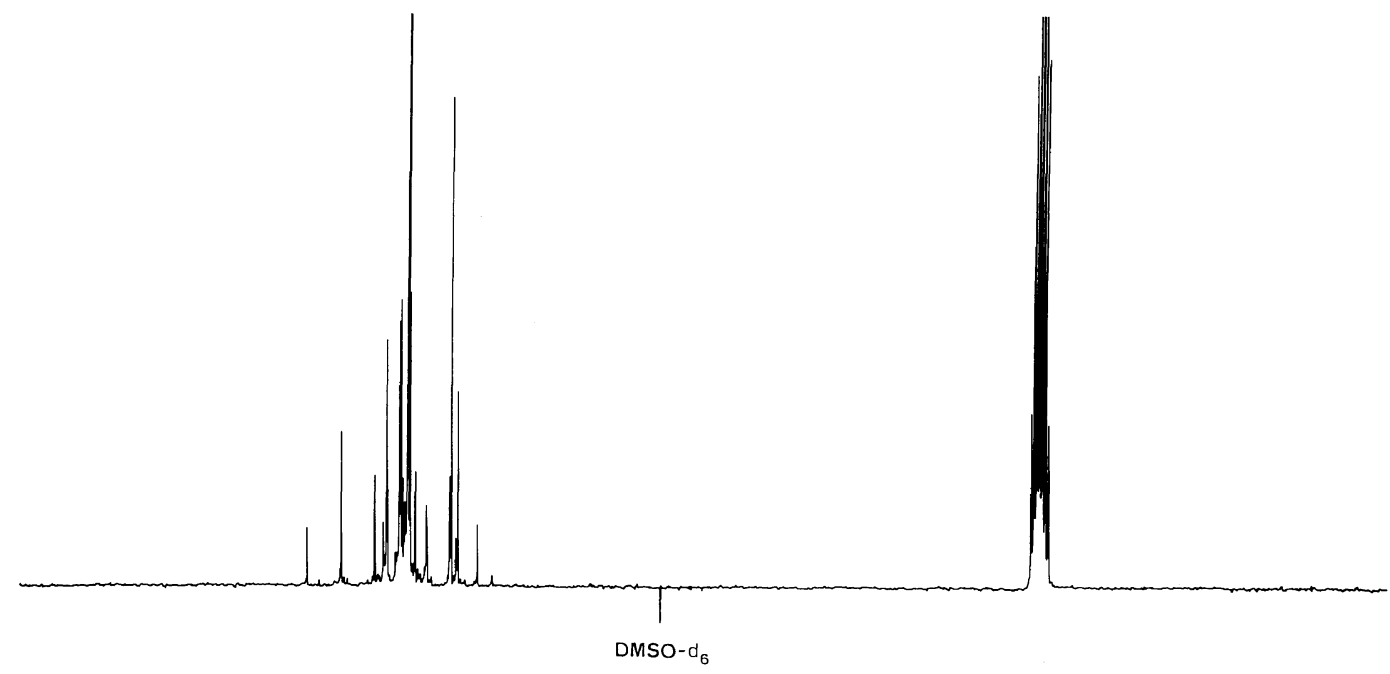

Figure 2. ${ }^{13} \mathrm{C}$ NMR spectrum of triarylsulfonium salts prepared by the method of Pitt (in DMSO- $d_{6}$ ). 
sensitivity. It was further anticipated that once having determined the key photoactive elements of the structure of these materials, it should be possible to use this information to design still other new highly photoactive photoinitiators.

The Friedel-Crafts reaction described by Pitt for the preparation of triarylsulfonium salts is run under conditions in which the stoichiometric ratio of the reagents benzene, sulfur monochloride and chlorine is $6: 1: 2$. It was observed that when this ratio was modified to $6: 2: 3$, the band at $300 \mathrm{~nm}$ in the UV intensified and the ${ }^{13} \mathrm{C}$ NMR showed little if any amount of triphenylsulfonium salt present. Correspondingly, the photoactivity of this material was even greater than that obtained using the stoichiometry described by Pitt. In fact, when the reaction product of this latter reaction was compared under identical conditions with the corresponding triphenylsulfonium salt in the photoinitiated cationic polymerization of epoxy resins, it was found to be four to five times more efficient. Considering the possible effects of the change in stoichiometry on the structure of the unknown compounds, it was postulated that the products of the reaction probably consisted of highly condensed or ring containing sulfonium salts. Shown below are the structures of some of the compounds which were considered to be reasonable candidates for the components present in the above mixture. The

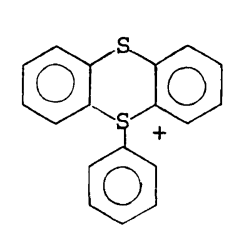

I



III



II

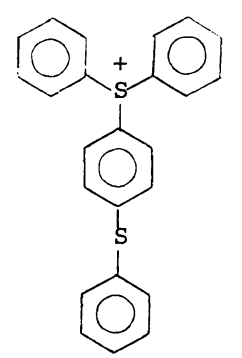

IV formation of these products can be rationalized as arising by a series of several Friedel-Crafts re- actions involving diphenyldisulfide, diphenylsufide, and phenylsulfenyl chloride as intermediates.

Fortunately, authentic samples of compounds I and IV could be readily prepared using a synthetic method recently developed in this laboratory ${ }^{9}$ and depicted in eq 1 and 2. Direct comparison of the UV


Figure 3. $\mathrm{UV}$ spectrum of $\mathrm{IV}$ in $\mathrm{CH}_{3} \mathrm{OH}$.

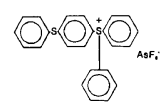

Polymer J., Vol. 17, No. 1, 1985 


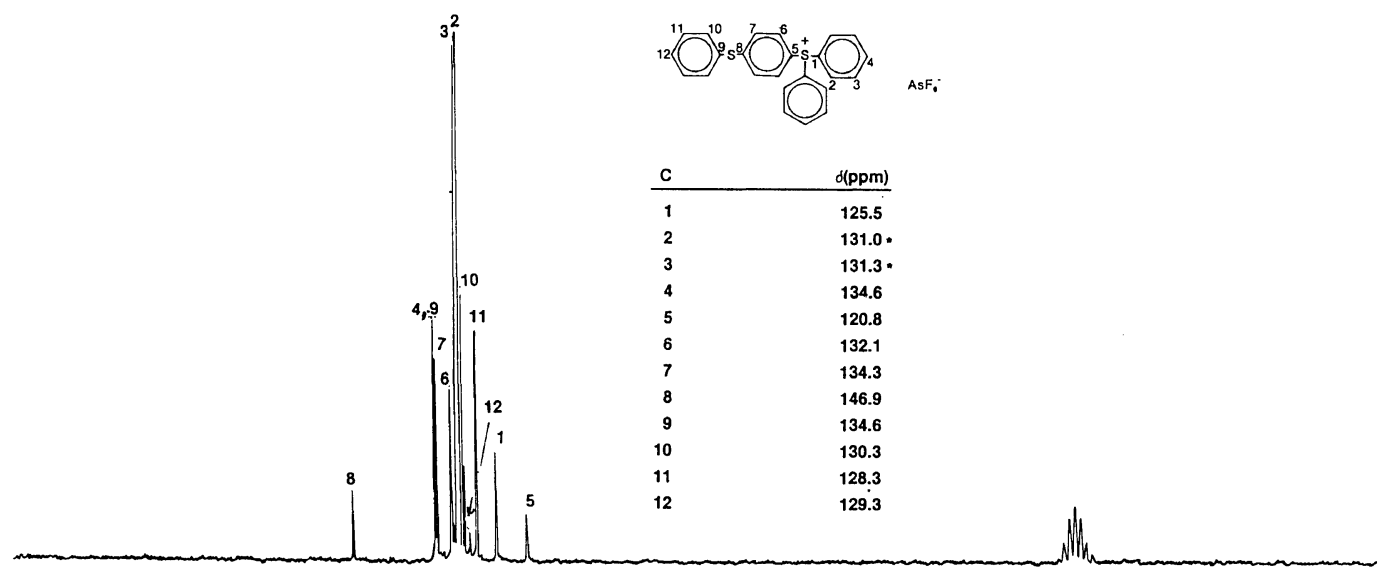

Figure 4. ${ }^{13} \mathrm{C}$ NMR spectrum of IV in DMSO- $d_{6}$.

(Figure 3) and ${ }^{13} \mathrm{C}$ NMR (Figure 4) spectra of compound IV with those of the mixtures prepared by the Pitt synthesis (Figures 1 and 2) and those obtained when this reaction was run under the modified stoichiometry described, indicated that IV is present in these mixtures in addition to the triphenylsulfonium salt. Recently, Watt and his coworkers ${ }^{10}$ have identified another related compound, $\mathbf{V}$, in this reaction mixture and have shown

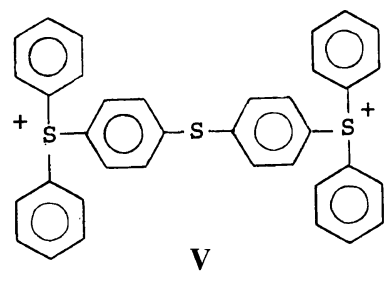

that it is present in substantial amounts.

The formation of the diphenyl-4-thiophenoxyphenylsulfonium cation, IV, can be explained as shown in eq $3-7$ as being derived from a series of reactions in which the key intermediate, diphenylsulfide, undergoes self condensation in the presence of chlorine and aluminum chloride.

$$
\begin{aligned}
& 2 \mathrm{C}_{6} \mathrm{H}_{6}+\mathrm{S}_{2} \mathrm{Cl}_{2} \\
& \stackrel{\mathrm{AlCl}_{3}}{\longrightarrow} \mathrm{C}_{6} \mathrm{H}_{5}-\mathrm{S}-\mathrm{S}-\mathrm{C}_{6} \mathrm{H}_{5}+2 \mathrm{HCl} \\
& \mathrm{C}_{6} \mathrm{H}_{5}-\mathrm{S}-\mathrm{S}-\mathrm{C}_{6} \mathrm{H}_{5}+\mathrm{CI}_{2} \\
& \longrightarrow \quad 2 \mathrm{C}_{6} \mathrm{H}_{5}-\mathrm{SCl}
\end{aligned}
$$

$$
\begin{aligned}
& \mathrm{C}_{6} \mathrm{H}_{5}-\mathrm{SCl}+\mathrm{C}_{6} \mathrm{H}_{6} \\
& \stackrel{\mathrm{AlCl}_{3}}{\longrightarrow} \quad\left(\mathrm{C}_{6} \mathrm{H}_{5} \hbar \mathrm{S}+\mathrm{HCl}\right. \\
& \left(\mathrm{C}_{6} \mathrm{H}_{5}+\frac{}{2} \mathrm{~S}+\mathrm{Cl}_{2} \longrightarrow\left(\mathrm{C}_{6} \mathrm{H}_{5}\right)_{2} \stackrel{+}{\mathrm{S}-\mathrm{Cl} \mathrm{Cl}}{ }^{-}\right. \\
& \left(\mathrm{C}_{6} \mathrm{H}_{5}\right)_{2} \stackrel{+}{\mathrm{S}-\mathrm{Cl} \mathrm{Cl}} \mathrm{Cl}^{-}+\left(\mathrm{C}_{6} \mathrm{H}_{5}\right)_{2} \mathrm{~S}
\end{aligned}
$$



If the above-proposed mechanism is correct, it should be possible to prepare IV directly from diphenyl sulfide as shown in eq 8 .
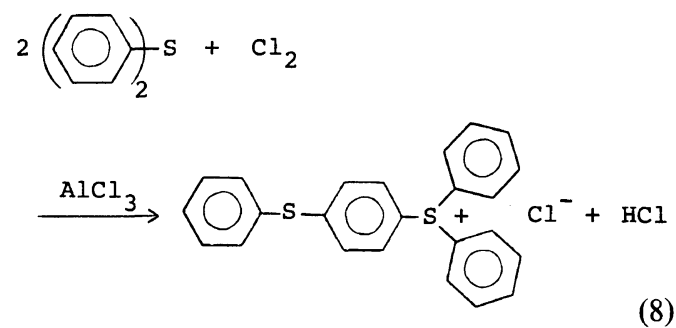

IV

Indeed, when this reaction was carried out, IV was obtained in good yields. This constitutes a new and convenient synthesis of IV which has been employed to good advantage for the synthesis of 


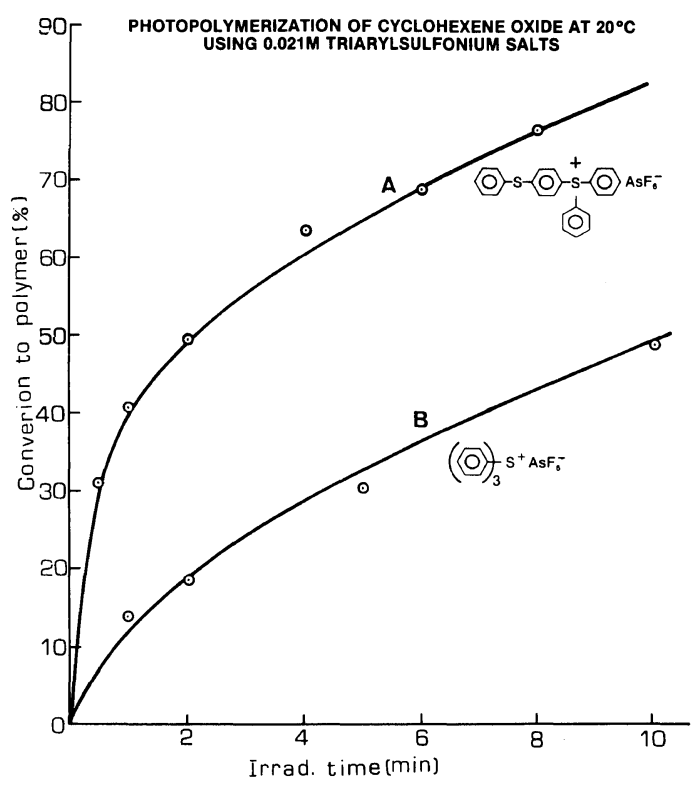

Figure 5. Photopolymerization of cyclohexene oxide at $20^{\circ} \mathrm{C}$ using $0.021 \mathrm{M}$ triarylsulfonium salts.

large amounts of these salts.

Figure 5 shows two curves obtained in a comparative study of the photopolymerization of cyclohexane oxide using triphenylsulfonium hexafluoroarsenate and the corresponding IV salt. Markedly higher polymerization rates and conversions were observed using photoinitiator IV because of its greater absorption characteristics at wavelengths above $300 \mathrm{~nm}$.

Clearly, the factor which distinguishes IV from its triphenylsulfonium salt counterpart and must ultimately account for its greater photoactivity is the presence in this compound of the thiophenoxy chromophor situated para with respect to the positively charged sulfur. Accordingly, it was decided to prepare a series of analogous compounds in which the effects of modification of this chromophor and its position within the molecule could be studied as a function of their photoactivity as cationic photoinitiators. Employing the same basic synthetic method as shown in eq 1 and 2, the openchain sulfonium salts shown in Table I were prepared.

As in the case of the triphenylsulfonium salts, when these compounds are irradiated at their absorption maxima, they undergo facile photolysis
Table I. Structure and spectral properties of open-chain triarylsulfonium salts



a All salts contained the $\mathrm{AsF}_{6}{ }^{-}$counterion.

b Spectra were recorded in methanol.

with the cleavage of one of the carbon-sulfur bonds of the sulfonium moiety. In the case of the diphenyl4-thiophenoxyphenylsulfonium cation, cleavage occurs in an almost completely regiospecific manner as depicted in eq 9. A glance at the $\lambda_{\max }$ of the

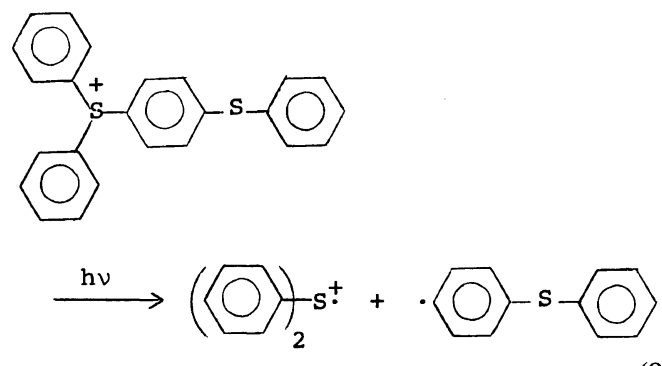




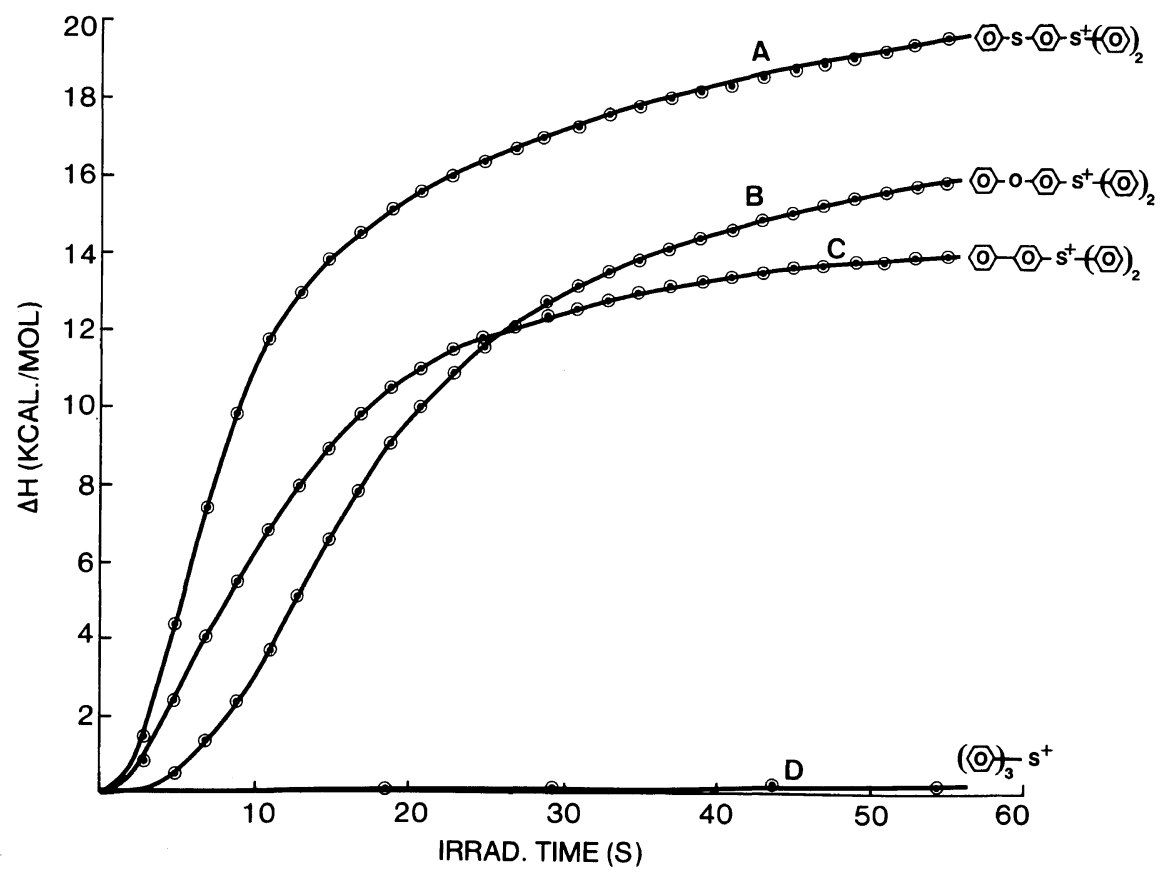

Figure 6. Photopolymerization of limonene oxide using $1 \mathrm{~mol} \%$ open chain triarylsulfonium salts (pyrex filtered GE H3T7 medium pressure $\mathrm{Hg}$ arc lamp).

compounds in Table I leads to the conclusion that the thiophenoxy chromophor is effective only when it is in the position para to the positively charged sulfur. The thiophenoxy group may be partially oxidized to the sulfoxide without substantially affecting the absorption characteristics; however, the corresponding sulfone has no absorption at long wavelengths. Further, replacement of the thiophenoxy moiety with the phenoxy or phenyl groups is less effective in shifting the $\lambda_{\max }$ to longer wavelengths. Figure 6 shows a comparison between a triphenylsulfonium salt and three of the sulfonium salts in Table I in the photoinitiated cationic polymerization of limonene dioxide using pyrex filtered light. At these wavelengths, the former salt is not a useful photoinitiator while the latter compounds give high rates of polymerization.

As part of our study of the Pitt reaction, cyclic sulfonium salt, $\mathbf{I}$, was prepared which had a $\lambda_{\max }$ at $310 \mathrm{~nm}(\varepsilon=5,650)$. Thus, it appeared that the absorption maximum could be shifted to longer wavelengths by bridging two of the aromatic groups through a sulfur atom. Accordingly, the method shown in eq 1 was again used to prepare several additional cyclic sulfonium salts of this type which are shown in Table II.

The relative efficiencies of these cyclic triarylsulfonium salts are shown in Figure 7 compared among themselves and against the analogous triphenylsulfonium salt in the photoinitiated cationic polymerization of limonene dioxide. From this and the previous figure, it may be concluded that while this approach to the design of long wavelength photoinitiators is effective, it is less so than the alternate means of attaching 4-thiophenoxy or 4phenylsulfoxy groups to the basic triphenylsulfonium chromophor.

\section{Thermally Initiated Cationic Polymerization}

It is remarkable that while triarylsulfonium salts initiate facile cationic polymerization when irradiated with UV light, in the absence of light they display no initiating activity whatsoever. In fact, triarylsulfonium salts may be heated to $150^{\circ} \mathrm{C}$ in the presence of epoxy monomers without inducing polymerization. Since there are numerous potential applications for initiators of cationic polymerization which have reasonable latency and can be 


\section{J. V. Crivello and J. L. LeE}

Table II. Structure and spectral properties of cyclic sulfonium salts

(2)

a All salts contained the $\mathrm{AsF}_{6}{ }^{-}$counterion.

b Spectra were recorded in methanol.

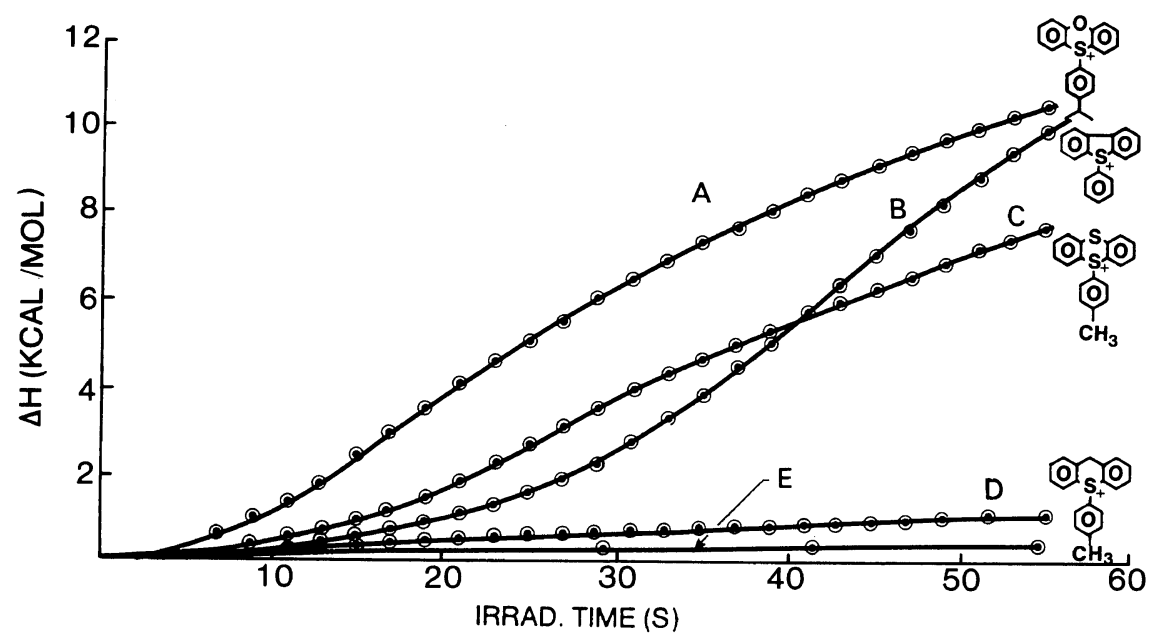

Figure 7. Photopolymerization of limonene oxide using $1 \mathrm{~mol} \%$ cyclic triarylsulfonium salts (pyrex filtered GE $\mathrm{H} 3 \mathrm{~T} 7$ medium pressure $\mathrm{Hg}$ arc lamp).

triggered thermally, we began to explore the possibility of using sulfonium salt photoinitiators for this purpose. Recently, in a paper from this laboratory, diaryliodonium salt photoinitiators were shown to be effective thermal initiators in the presence of $\mathrm{Cu}(\mathrm{I})$ compounds $^{11}$ as reducing agents. Similar 
attempts to reduce triarylsulfonium salts met with little success probably due to the high reduction potential of these salts $\left(-28 \mathrm{kcal} \mathrm{mol}^{-1}\right)$ compared to the diaryliodonium salts $\left(-5 \mathrm{kcal} \mathrm{mol}^{-1}\right)$. Dialkylphenacylsulfonium salts, VI, are another

$$
\stackrel{\mathrm{II}}{\mathrm{Ar}-\mathrm{C}-\mathrm{CH}_{2}-\mathrm{SR}_{2}} \underset{\mathrm{x}}{+}
$$

VI

class of sulfonium salts which have both excellent photosensitivity and stability towards thermally induced decomposition. ${ }^{12}$ Moreover, these latter compounds have a substantially lower reduction potential $\left(-14.5 \mathrm{kcal} \mathrm{mol}^{-1}\right)^{13}$ than the triarylsulfonium salts and were, therefore, considered better candidates for thermal initiators. Indeed, it was observed that ferrocene and arylthiols are active reducing agents for dialkylphenacylsulfonium salts. In the presence of such agents, dialkylphenacylsulfonium salts will initiate cationic polymerization at temperatures above $100^{\circ} \mathrm{C}$. Similarly, these sulfonium salts will initiate polymerization as shown in Figure 8 when thermolyzed in the presence of such common free radical sources as benzoyl peroxide. The mechanism which we propose for this reaction is shown in eq 10-15. By selection of the free radical

$$
\mathrm{Bz}_{2} \mathrm{O}_{2} \stackrel{\Delta}{\longrightarrow} 2 \mathrm{BzO} \cdot \longrightarrow 2 \mathrm{Ph} \cdot+2 \mathrm{CO}_{2}
$$<smiles>[R]C1CCCCO1</smiles>

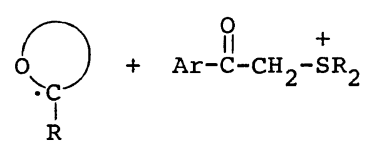
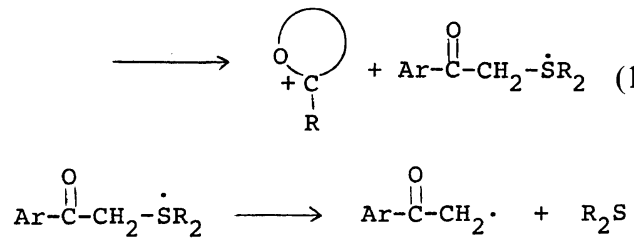<smiles>[R]C1=CCCCO1</smiles>

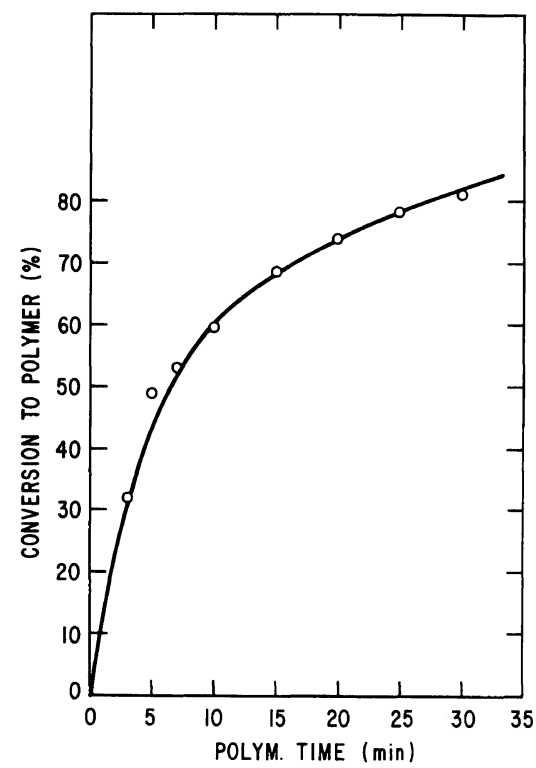

Figure 8. Bulk polymerization of styrene oxide at $90^{\circ} \mathrm{C}$ using $5 \times 10^{-2} \mathrm{M}\left\langle\mathrm{O}-\stackrel{\mathrm{I}}{\mathrm{C}}-\mathrm{CH}_{2} \stackrel{+}{-} \mathrm{SbF}_{6}{ }^{-}\right.$and $5 \times 10^{-2} \mathrm{M}$ benzoyl peroxide.



source with the appropriate decomposition rate and half-life, it is possible to design an initiator system for virtually any desired temperature between 80 and $200^{\circ} \mathrm{C}$. Yet another series of thermally activated cationic initiators based on dialkyl-4-hydroxyphenylsulfonium salts, VII, has been developed.<smiles>[R]c1cc([Sb]([R])([R])[X])cc([R])c1O</smiles>

It has been found that these sulfonium salts are susceptible to oxidation by such oxidants as quinones and iodosobenzene diacetate. The redox mechanism shown in eq 16 is proposed for the reaction of 2,3-dichloro-5,6-dicyanobenzoquinone (DDQ) with the dialkyl-4-hydroxyphenylsulfonium salt. A similar mechanism can be written 


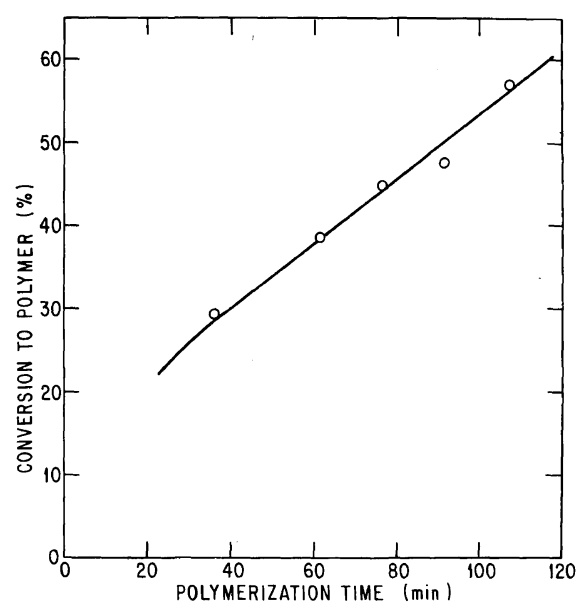

Figure 9. Bulk polymerization of cyclohexene oxide $(0.1 \mathrm{~mol})$ at $30^{\circ} \mathrm{C}$ using $\mathrm{CH}_{3} \mathrm{O}$

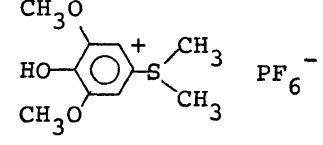

$\left(7 \times 10^{-4} \mathrm{~mol}\right)$ and DDQ $\left(1.4 \times 10^{-3} \mathrm{~mol}\right)$.

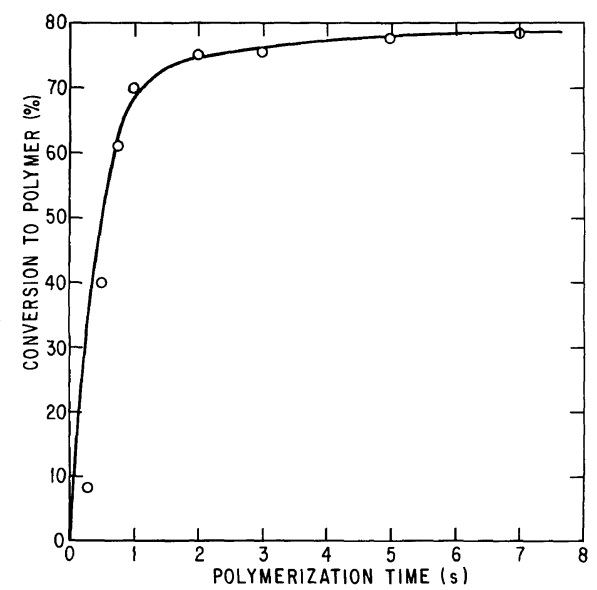

Figure 10. Solution polymerization of cyclohexene oxide $(0.1 \mathrm{~mol})$ at $28^{\circ} \mathrm{C}$ in nitrobenzene $(20 \mathrm{ml})$ using<smiles>COc1cc(S(C)(C)CP)cc(OC)c1O</smiles>

$\left(7 \times 10^{-4} \mathrm{~mol}\right)$ and $\mathrm{C}_{6} \mathrm{H}_{5} \mathrm{I}\left(\mathrm{O}_{2} \mathrm{C}-\mathrm{CH}_{3}\right)_{2}\left(7 \times 10^{-4} \mathrm{~mol}\right)$.

in which iodosobenzene diacetate is the oxidant. Figures 9 and 10 give the conversion versus time curves for the polymerization of cyclohexene oxide using the above two initiating systems.
In conclusion, sulfonium salts are a new and useful class of latent initiators for cationic polymerization whose activity may be triggered either photochemically or thermally. Through judicious manipulation of the structures of these compounds, it has been shown possible to design photoinitiators which have their maximum response as desired at either long or short wavelengths in the UV. Similarly, sulfonium salt-redox systems are easily constructed which initiate cationic polymerization thermally at temperatures ranging from 25 to $200^{\circ} \mathrm{C}$.<smiles>COc1ccccc1</smiles><smiles>[R][As]c1ccc(O)cc1</smiles><smiles>[R7][S+]([R7])c1ccc([O-])cc1</smiles><smiles>[R][SH]([R7])c1ccc(OC2([SH]([R7])[R5])C=CC(=O)C=C2)cc1</smiles><smiles>[R]C(C)C#CC</smiles>

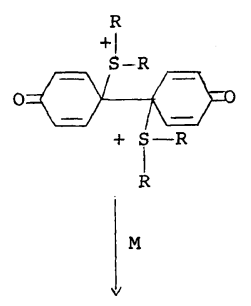<smiles>O=C1C=CC(=C2C=CC([18OH+])C=C2)C=C1</smiles><smiles></smiles>

\section{REFERENCES}

1. J. V. Crivello and J. H. W. Lam, J. Polym. Sci., Polym. Chem. Ed., 17, 977 (1979).

2. J. V. Crivello and J. H. W. Lam, J. Polym. Sci., Polym. Symp., 56, 383 (1976).

3. J. V. Crivello and J. H. W. Lam, Macromolecules, 10, 1307 (1977).

4. J. V. Crivello and J. H. W. Lam, J. Polym. Sci., Polym. Chem. Ed., 17, 2877 (1979).

5. J. V. Crivello and J. H. W. Lam, J. Polym. Sci., Polym. Chem. Ed., 18, 1021 (1980). 
6. J. E. Moore, S. H. Schroeter, A. R. Schultz, and L. D. Stang, ACS Polym. Symp. Ser., 25, 9 (1976).

7. C. Courtot and T. Y. Tung, C. R. Acad. Sci., Ser. C, 197, 1227 (1933).

8. H. M. Pitt, U.S. Patent 2,807,648, May 6, 1958; Chem. Abstr., 52, 2910d (1958).

9. J. V. Crivello and J. H. W. Lam, J. Org. Chem., 43, 3055 (1978).
10. K. T. Chang, U.S. Patents 4,197,174 and 4,247, 473, Apr. 8, 1980, and W. R. Watt, U.S. Patents 4,201,640 and 4,247,472, May 6, 1980.

11. J. V. Crivello, T. P. Lockhart and, J. L. Lee, J. Polym. Chem., Polym. Chem. Ed., 21, 97 (1983).

12. J. V. Crivello and J. L. Lee, Macromolecules, 16, 864 (1983).

13. J. M. Saveant, C. R. Hebd. Seances. Acad. Sci. Ser. $C$, 256, 589 (1964). 